\title{
CRÔNICA DE UMA TRADUTORA ANUNCIADA: CLARICE E A TRADUÇÃO COMO DEVER
}

\section{CHRONICLE OF A TRANSLATOR FORETOLD: CLARICE AND TRANSLATION AS A DUTY}

\author{
Rony Márcio Cardoso Ferreira \\ Universidade de Brasília \\ Brasília, Brasília, Brasil \\ Germana Henriques Pereira \\ Universidade de Brasília \\ Brasília, Brasília, Brasil
}

RESUMO: Clarice Lispector tornou-se conhecida por renovar a prosa intimista da literatura brasileira durante o século XX. Além de escritora, foi jornalista, repórter e entrevistadora na imprensa carioca, sem contar o seu ofício de tradutora, por meio do qual assinou a versão de cerca de 46 textos em língua portuguesa, entre eles romances, contos e peças teatrais. Contudo, seus trabalhos de tradução ficaram de lado quando se discutiu, no cenário da crítica, o peculiar caminho de seu projeto literário. Nesse sentido, o presente artigo visa a um estudo da primeira tradução assinada por Clarice antes mesmo da publicação de Perto do coração selvagem (1943): a versão em português do conto "Le missionnaire" (1921), de Claude Farrère. Em outras palavras, este estudo procura evidenciar o lugar sintomático da tradução diante do projeto da escritoratradutora, mesmo antes da publicação de seu primeiro romance. Para tanto, a partir dos estudos da tradução literária, esta reflexão volta-se à versão em língua portuguesa do conto francês, procurando tomá-la como um dos marcos iniciais do percurso de Clarice enquanto tradutora. Percurso este que nunca esteve dissociado de seu projeto, mesmo quando a jovem Lispector era ainda uma desconhecida nas letras nacionais.

Palavras-chave: Tradução literária; Clarice Lispector tradutora; Literatura brasileira

\begin{abstract}
Clarice Lispector became known for renovating the intimate prose of Brazilian literature during the 20th century. In addition to being a writer, she was a journalist, a reporter and an interviewer in the Rio de Janeiro press, not to mention her role as a translator, through which she signed the version of about 46 texts, including novels, short stories and plays. However, her translation works were bypassed when the peculiar path of her literary project was discussed in the
\end{abstract}


context of criticism. In this sense, this article aims at a study of the first translation signed by Clarice even before the publication of Perto do Coração Selvagem (1943): the Portuguese version of the short story "Le missionnaire" (1921) by Claude Farrère. In other words, this study seeks to highlight the symptomatic place of translation in face of the writertranslator's project, even before the publication of her very first novel. To do so, starting from the studies of literary translation, this reflection revolves around the Portuguese version of the French tale, seeking to take it as one of the initial milestones of Clarice's journey as a translator. This path has never been dissociated from her project, even when the young Lispector was still unknown in the national literature.

Keywords: Literary translation; Clarice Lispector translator; Brazilian literature 


\section{A década de 1940 e a jovem escritora}

Respeito os autores que traduzo, é claro, mas procuro me ligar mais no sentido do que nas palavras. Estas são bem minhas, são as que elejo (LISPECTOR, apud COUTINHO, 1980, p. 166).

Na crônica "O primeiro livro de cada uma de minhas vidas", publicada em fevereiro de 1973, no Jornal do Brasil, Lispector afirma que a leitura e a escrita já se faziam presentes, simultaneamente, em sua vida, quando, a partir de um empréstimo em uma biblioteca popular de aluguel, teve contato com a chamada grande literatura, ao ler $O$ lobo da estepe, de Herman Hesse. Além de Hesse, a menina leitora fisgada pela história do patinho feio e da lâmpada de Aladim logo se apaixonaria também pela literatura de Monteiro Lobato e Katherine Mansfield. $\mathrm{Na}$ escrita, o ato de fabular acontecia, porém seus contos eram recusados pelo Diário de Pernambuco, na década de 1930, pois não narravam fatos, mas sensações (Cf. GOTLIB, 2008, p. 86).

A adolescente, que escolhera o livro pelo título, afirmou ter sido germinada por Hesse e impulsionada a escrever um conto imitando o escritor alemão: "dos 13 aos 14 anos fui germinada por Herman Hesse e comecei a escrever um longo conto imitando-o: a viagem interior me fascinava. Eu havia entrado em contato com a grande literatura" (LISPECTOR, 1999, p. 453). Pouco tempo depois, Lispector leria Mansfield sem nem imaginar que lia uma importante escritora de seu tempo, no mesmo ano em que tem seu primeiro conto ("O triunfo") publicado na revista Pan (Cf. LISPECTOR, 2007, p. 19). Segundo Nádia B. Gotlib (2008), Clarice leu Bliss, de Mansfield, por meio da tradução de Érico Veríssimo, publicada pela editora da Livraria O Globo de Porto Alegre, em 1940. Quanto ao livro de Hesse, a tradução lida pela jovem Lispector foi possivelmente da lavra de Augusto de Souza, publicada em 1935, pela Edições da Cultura Brasileira (Cf. GOTLIB, 2008, p. 108, 122).

No início da década de 1940, Clarice, então estudante de Direito, começou a trabalhar como jornalista na Agência Nacional do Departamento de Imprensa e Propaganda (DIP), órgão governamental cuja finalidade era a de propagar notícias do governo de Getúlio Vargas. Neste período, conheceu alguns escritores que também trabalhavam no Departamento, entre eles Antonio Callado e Lúcio Cardoso, com os quais estabeleceu uma amizade duradoura, registrada em cartas compiladas, atualmente, em Correspondências (2002), volume organizado por Teresa Montero. Foi nesse contexto que o projeto literário da escritora começou a ser pontualmente esboçado, como se o espaço do edifício A Noite, localizado na Praça Mauá, centro do Rio de Janeiro, além de local de trabalho, fosse o ambiente propício para o aparecimento da escritora, chamada por Antonio Candido de "a origem das tendências desestruturantes" da literatura brasileira (2011, p. 254).

Vale ressaltar que Clarice foi "contratada como tradutora em 1940" (MONTERO, 2018, p. 34), passando também a exercer as funções de redatora e repórter. Nesse mesmo edifício, funcionava o corpo editorial da Revista Vamos Lêr (1936 - 1948), onde a escritora teve sua primeira tradução publicada: uma 
versão em português do conto "Le missionnaire" (1921), de Claude Farrère. Essa publicação, ocorrida em 06 de fevereiro de 1941, por mais que apresentasse o nome da desconhecida tradutora grafado erroneamente (Clarice com dois "s" "Clarisse"), prenunciou, de certa maneira, uma das atividades a que se dedicaria, ao longo dos anos. Abaixo seguem algumas imagens da revista, com destaque para o o nome da autora grafado como "Clarisse":
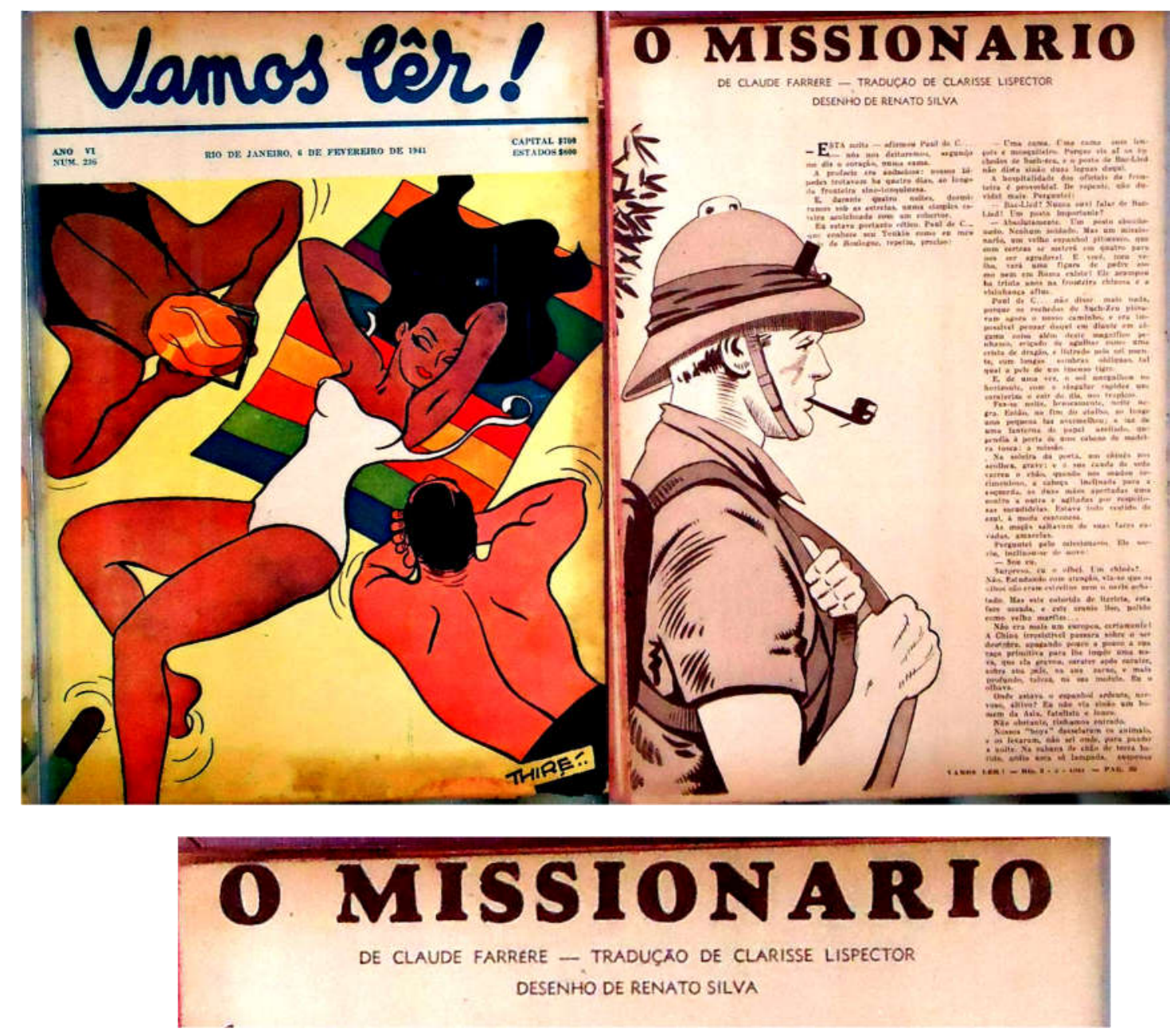

Imagem 01 - Capa da Revista Vamos lêr, Ano VI, n. 236, seguida da primeira página da versão em português do conto "Le missionnaire", de Claude Farrère, assinada por

Clarice Lispector em 1941.

Cabe salientar que esse não foi o primeiro contato de Lispector com o ofício da tradução, pois a escritora também traduziu textos e documentos oficiais enquanto esteve na Agência Nacional, como bem afirma em carta escrita a Elisa, sua irmã, em maio de 1940: "Recebi na $2^{\mathrm{a}}$ feira $281 \$ 200$ na redação concernente a traduções antigas" (LISPECTOR, 2007, p. 18). Quem sabe sufocada diante da estranheza sentida pelos críticos com a proposta de Perto do coração selvagem (1943), a pequena tarefa da tradução do conto francês, quando não passou despercebida aos olhos da crítica, apenas rendeu uma ou outra rápida menção nas mais importantes biografias sobre a escritora, a exemplo de Clarice: uma vida que se conta (2009) e Clarice Fotobiografia (2008), de Nádia Batella Gotlib; 
Clarice (2009), de Benjamin Moser; e Eu sou uma pergunta (1999), de Teresa Cristina Montero.

Talvez porque Clarice estivesse muito perto do coração, a crítica ocupouse em tecer elogios e/ou depreciar seu primeiro trabalho como escritora, fazendo da tradução do pequeno conto uma parte sem importância de seu projeto intelectual como um todo, esquecendo-se de que essa atividade se tornaria tão intensa e caótica quanto a sua própria literatura na década de 1970. Tímida e descolada do grande conjunto de obras que traduziu posteriormente, a única tradução publicada por Lispector em quase duas décadas (1940 e 1950) torna-se importante quando se propõe o exame do papel da escritora-tradutora no contexto maior de seu projeto, pois a versão de 1941 já sinaliza, sintomaticamente, o início do percurso de Clarice Lispector tradutora, ainda que a sua prática de tradução só fosse retomada mais intensamente quando a intelectual necessitou complementar seus rendimentos financeiros, a partir da década de 1960.

\section{Lispector tradutora de Farrère ou da tradução como hospitalidade}

Rio de Janeiro, 3 de junho de 1942.

Senhor Presidente Getúlio Vargas:

Quem lhe escreve é uma jornalista, ex-redatora da Agência Nacional (Departamento de Imprensa e Propaganda), atualmente n'A Noite, acadêmica da Faculdade Nacional de Direito e, casualmente, russa também (LISPECTOR, 2002, p. 33).

Esse é o início da carta que Clarice Lispector escreveu a Getúlio Vargas, em 1942, na intenção de lhe solicitar dispensa do prazo de um ano necessário para o processo de sua naturalização que tramitava pelo Ministério da Justiça. Ao se apresentar ao Presidente, a estudante de Direito afirma ser jornalista n'A Noite, ex-funcionária do DIP, "uma russa de 21 anos de idade e que está no Brasil há 21 anos e alguns meses. Que não conhece uma só palavra em russo mas que pensa, fala, escreve e age em português [...]. Que se fosse obrigada a voltar à Rússia, lá se sentiria irremediavelmente estrangeira" (LISPECTOR, 2002, p. 33). Pouco antes da escrita da carta, a jovem jornalista publicou na Revista Vamos Lêr os contos "Eu e Jimmy" (1940) e "Trecho" (1941) (Cf. LISPECTOR, 2005, p. 10, 23), quando então assinou também seu primeiro trabalho como tradutora: a versão em português do conto "Le missionnaire", de Claude Farrère".

\footnotetext{
${ }^{1}$ Segundo Teresa Montero e Lícia Manzo (2005), a jovem estudante procurou Lourival Fernandes, diretor do DIP (Departamento de Imprensa e Propaganda), em 1940, para solicitar uma vaga de emprego como tradutora (Cf. MONTERO; MANZO, 2005, p. 31). Entretanto, como o quadro de tradutores estava completo, Lispector foi admitida na função de repórter e redatora da Agência Nacional que era vinculada ao DIP.
} 
O conto francês foi originalmente publicado no livro Contes d'outre $e$ d'autre mondes, editado pela Librairie Dorbon-Ainé, em 1921, com a tiragem de 1000 exemplares:
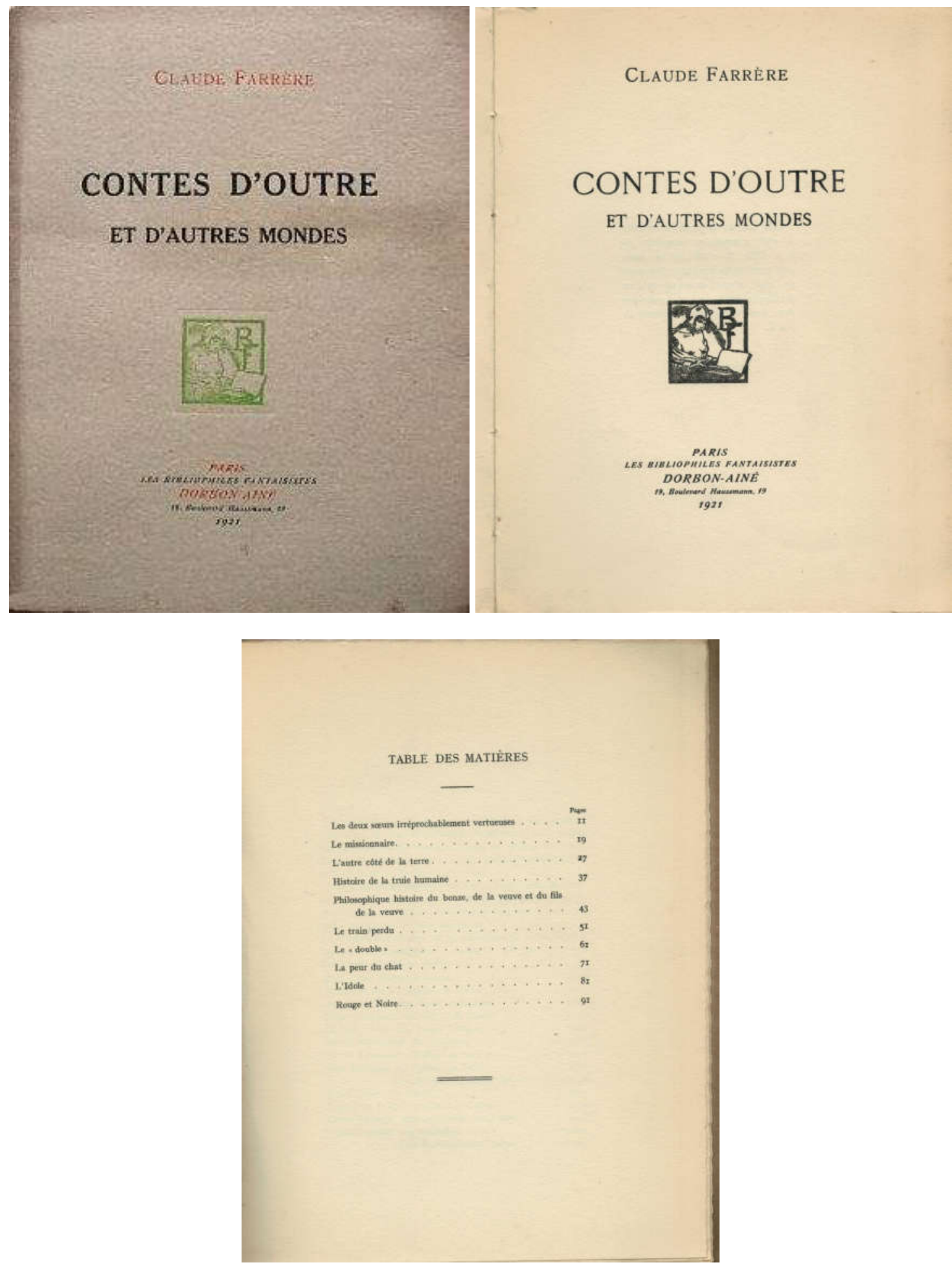

Imagem 02 - Capa de Contes d'outre et d'autres mondes, de Claude Farrère (1921), seguida da folha de rosto e do sumário (exemplar de número 815 ). 
O escritor francês - que, na verdade, chamava-se Frédéric Charles Bargone e assinava suas obras com o pseudônimo Claude Farrère -, além de ensaísta e historiador, tornou-se capitão da Marinha Nacional da França, em 1918. No ano seguinte, pediu demissão do cargo para se dedicar exclusivamente à literatura. Foi membro da Academia Francesa de Letras a partir de 1935, ocupando a cadeira de número 28. Devido às expedições que fizera, à época do serviço naval, conheceu várias partes do mundo (entre elas, o continente asiático), onde ouviu inúmeras histórias em casas de ópio que permeiam toda a sua ficção, a exemplo do romance Fumée d'opium (1904). De modo geral, as obras de Farrère, publicadas entre 1902 e 1955, enquadram-se no que conhecemos por literatura de viagens e versam a respeito de suas impressões do Extremo Oriente e experiências de guerra, sempre atravessadas pela relação do escritor com o $\operatorname{mar}^{2}$. Entre suas mais conhecidas obras está o romance Les civilisés (1905), vencedor do Prêmio Goncourt do ano de 1905, além do livro que escreveu sobre a marinha francesa: Histoire de la Marine française (1934).

O conto "Le missionnaire" narra, basicamente, a história de um narradorpersonagem parisiense e do vietnamita Paul de C., que caminham pela fronteira entre a China e o Vietnã. A narração, ambientada no período neocolonial em que os franceses dominaram a península da Indochina, problematiza a chegada do oficial francês e do guia vietnamita a um posto de batalha abandonado na região fronteiriça, por sua vez, habitado por um missionário espanhol - padre católico que vivia nessa fronteira há mais de 30 anos, em uma modesta cabana de madeira (a missão) - e seu criado chinês. A narrativa até aqui parece nada problematizar. Entretanto, o conflito narrativo vê-se pontuado quando o narrador, juntamente com Paul de C., chega à cabana do missionário e, pelo estereótipo das vestimentas cantonesas, julga-lhe chinês. Esse julgamento logo é reiterado por meio do discurso do narrador que, mesmo depois de identificar a ascendência europeia do missionário, dizia ver não um "espanhol ardente", mas sim "um homem da Ásia, fatalista e louco" (FARRÈRE, 1941, p. 32), momento em que o próprio missionário afirma: "- Há... tanto tempo... trinta anos... que eu sou... chinês" (FARRÈRE, 1941, p. 32).

O missionário, que "quase esquecera as línguas inúteis do Ocidente" (FARRÈRE, 1941, p. 33), comenta, em resposta à indagação de Paul de C., sobre o fracasso de sua longa expedição missionária, devido à idolatria dos chineses, fato que o impossibilitou de batizar muitos novos cristãos. A maior surpresa do narrador e do vietnamita, no plano narrativo, dá-se quando constatam que o padre era fumante de ópio: "- Antes de dormir... fumo sempre doze cachimbos..." (FARRÈRE, 1941, p. 33). Surpresa essa que parece superada pelas ações de hospitalidade do missionário e por outra constatação mais impactante ainda

\footnotetext{
${ }^{2}$ Na página virtual da Academia Francesa de Letras, encontra-se reproduzido um artigo de Claude Farrère intitulado "Marins et littérateurs" em que o autor trata da importância da figura do marinheiro (viajante) na literatura ocidental. Para tanto, vale-se de célebres personagens Ulisses (da Odisseia, de Homero) e Vasco da Gama (de Os Lusíadas) de Camões, entre outros navegantes franceses - para mostrar o quanto o mar se põe como esplêndido cenário que motivou vários viajantes nos relatos de suas aventuras (Cf. FARRĖRE, 1946).
} 
verificada no dia seguinte: há 30 anos, o padre obedientemente rezava missas de manhã, mesmo não tendo um fiel à sua frente: "Nem conversões, nem fiéis... nem consolações..." (FARRÈRE, 1941, p. 64). Esse contexto leva o narrador a comentar apenas dois aspectos que realmente marcavam a vida do missionário: a obediência e os cachimbos.

A tradução feita por Clarice Lispector mantém, em âmbitos gerais, o que é proposto por Claude Farrère, no âmbito da linguagem e do conflito narrativo. Tanto a tradução quanto o texto em francês são apresentados ao leitor de forma clara, direta e sem entraves de leitura. Talvez aí estivesse uma das justificativas em se publicar um conto dessa natureza em uma revista com os propósitos da Vamos Lêr. Como periódico de fácil acesso, a revista abordava temas gerais, mesclados, em um ato pioneiro no Brasil, à publicação de artigos científicos, todos escritos com uma linguagem simples e acessível. Junto a esse propósito maior, também publicava textos de renomados escritores (Jorge Amado, por exemplo) e de jovens que viriam a se consagrar como escritores nas décadas seguintes (entre eles, Clarice Lispector e Fernando Sabino), além de alguns textos com assuntos políticos, como aqueles relativos à Segunda Guerra Mundial ${ }^{3}$.

Segundo Ana Luiza Martins (2008), o periódico reproduzia um modelo de revistas francesas do início do século XX, a exemplo da Je sais tout, encyclopédie mondiale illustrée, e contava com a direção de Raimundo Magalhães, sendo impressa em papel-jornal de baixo custo, o que garantia ampla circulação nacional. Nas palavras de Martins, Vamos Lêr e outras revistas brasileiras do período confirmavam "a importação da fatura periódica francesa, agora voltadas para o seguimento de consumo médio, definido sobretudo pela faixa etária escolar, estimulada pela recente alfabetização de algumas capitais do país" (MARTINS, 2008, p. 96).

A tradução da narrativa francesa vem ilustrada por Renato Silva ${ }^{4}$ e omite a dedicatória presente no original de 1921, em que Farrère dedica o pequeno conto a Edmond Jaloux, escritor, crítico literário e membro da Academia Francesa de Letras a partir de 1937. As diferenças são notadas não apenas nas comparações que podem ser feitas a partir dos suportes em que o texto em francês e a sua tradução tornam-se públicos (um livro de contos em língua francesa e uma revista carioca de ampla circulação, respectivamente), fato esse que faz com que o texto em língua portuguesa seja logo identificado, depois do título, como uma tradução, antecedendo o nome do autor das imagens ilustrativas do conto. Aqui, estamos

\footnotetext{
${ }^{3}$ No artigo intitulado "História da Propaganda Brasileira em Revista no Período da Segunda Guerra Mundial. um estudo exploratório", Flailda Garboggini e Adalgisa Caruso afirmam que "Vamos ler! era uma publicação mais politizada. Jorge Amado foi um de seus colaboradores. Essa revista publicava artigos de divulgação científica. Propriedade da S.A. A Noite, no Rio de Janeiro, foi lançada no Brasil por volta de 1935 com circulação nacional. Apresentava ilustração de capa com o assunto mais importante da semana ou algo a ele ligado, através de desenhos ou fotos trabalhadas com alguns traços" (GARBOGGINI; CARUSO, 2007, p. 4).

${ }^{4}$ Formado pela Escola Nacional de Belas Artes, Renato Silva passou trabalhar como ilustrador de histórias em quadrinhos a partir de 1925. Seu livro mais conhecido é Manual Prático de Desenho, que foi reeditado em 2012 pela editora Criativo.
} 
bem próximos do que Marie-Hélène Torres (2011) entende por visualização da tradução.

Com base na teoria do paratexto ${ }^{5}$, Torres afirma a importância do estabelecimento de três questionamentos prévios que podem auxiliar, em diferentes níveis, na leitura crítica de um texto em tradução: "como se apresenta a tradução? O que nos mostra o paratexto? O texto traduzido apresenta-se como uma tradução assumida? ${ }^{6}$ (TORRES, 2011, p. 18, grifo da autora). Ao observarmos a forma como a tradução se apresenta, estaríamos mais no campo do que se entende por leitura dos índices morfológicos das traduções, constituídos por capas, contracapas, página de rosto (Cf. TORRES, 2011, p. 19). A nosso ver, em amplo sentido, já estariam aí os vestígios de que toda tradução, de uma forma ou de outra, no próprio texto ou em seu contexto, já se apresenta enquanto um texto outro, um texto em sua diferença, desde quando nos voltamos para o suporte em que ele se materializa na cultura de chegada. No caso do conto traduzido por Lispector, parece não ter ocorrido de outro modo.

Entretanto, as diferenças não param por aí. Logo nos primeiros parágrafos do texto em português há duas interferências da tradutora dignas de menção, mas que não afetam o propósito básico de Clarice tal como explicitado em "Traduzir procurando não trair" (1968). Além disso, vale ressaltar que, na década de 1940, Lispector talvez não tivesse ainda, em mente, esse projeto, que vai se firmando ao longo dos anos. A primeira delas refere-se ao fato de que Lispector verte a expressão "si le cœur nous dit" por "segundo me diz o coração", fazendo uma tradução quase literal da expressão idiomática francesa, que significa "se nos aprouver". Segundo o estudioso, a expressão, na verdade, significa "se é o que the agrada; se lhe apraz". Para ficarmos mais próximos da proposta de Clarice ou do estilo mais simples utilizado pelo próprio autor em toda a narrativa, podemos dizer que a expressão também não deixa de significar "se nos der vontade", "se nós quisermos". Ao tentar se aproximar ao máximo do texto francês (preservando o termo "cœur/coração"), a tradutora deixa, em língua portuguesa, o texto ainda mais poético, fazendo com que o enigmático personagem Paul de C..., assim como a própria escritora e muitas outras personagens dos romances clariceanos, mostrem-se muito Perto do coração selvagem. Isso se dá porque a tradutora modaliza a pessoa do verbo deixando a frase mais íntima e pessoal. Diríamos mais: há uma tradutora preocupada com uma fidelidade à legião estrangeira do texto de partida, mas que, talvez inconscientemente, não deixa de ser fiel ao seu projeto literário. Comparando os primeiros parágrafos do texto em francês à tradução de 1941, temos:

\footnotetext{
${ }^{5}$ A noção de paratexto que permeia a proposta de Torres (2011) é aquela definida por Gérard Genette. O estudioso francês afirma que um texto sempre apresenta-se com "o reforço e o acompanhamento de certo número de produções, verbais ou não, como um nome de um autor, um título, um prefácio, ilustrações, que nunca sabemos se devemos considerar, mas que, em todo caso, o cercam e o prolongam, exatamente para apresentá-lo" (GENETTE apud TORRES, 2011, p. 19).

${ }^{6}$ Cf. Assumed translation, expressão empregada por Gideon Toury em Descriptive Translation Studies and Beyond. Amsterdam: Benjamin, 1995.
} 
Ce soir, affirma Paul de C..., nous coucherons, si le cour nous dit, dans un lit.

La prophétie était audacieuse: nos bidets trotaient depuis quatre jours, le long de la frontière sino-tonkinoise. Et, quatre nuits durant, nous avions dormi à la belle étoile, sur une simples natte matelassée d'une couverture.

J'etais donc sceptique. Paul de C..., qui connaît son Tonkin, comme moi mon Bois de Boulogne, répéta, précis:

- Dans un lit. Un lit avec draps et moustiquaire. Car voici les rochers de Such-Zen, e le poste de Bac-Liet n'est pas à deux lieues d'ici (FARRÈRE, 1921, p. 19 , grifos nossos).
- Esta noite - afirmou Paul de C... - nós nos deitaremos, segundo me diz o coração, numa cama.

A profecia era audaciosa: nossos bípedes trotavam há quatro dias, ao longo da fronteira sino-tonquinesa.

$\mathrm{E}$, durante quatro noites, dormimos sob as estrelas, numa simples esteira acolchoada com um cobertor.

Eu estava portanto cético. Paul de C... que conhece seu Tonkin como eu meu Bois de Boulogne, repetiu, preciso:

- Uma cama. Uma cama com lençóis e mosqueteiro. Porque eis os rochedos de Sush-Zen, e o posto de Bac-Liet não dista senão duas léguas daqui (FARRÈRE, 1941, p. 32, grifos nossos).

A divisão dos parágrafos do texto em português não segue a estruturação proposta pelo texto de partida. Essa diferenciação pode ser notada não só quando relacionamos os fragmentos acima, mas também quando observamos o texto em francês e a tradução como um todo. Essa mudança na divisão dos parágrafos pode ter ocorrido em virtude da editoração do conto ao lado das ilustrações de Renato da Silva, provavelmente por falta de espaço nas páginas 32 e 33, já que os últimos parágrafos do texto em português são reproduzidos na página 64 da revista, prática essa muito comum à época. Finalmente, a publicação dessa versão por encomenda parece problematizar o que Lefevere (2007) entende por "patronagem". Para o estudioso, toda tradução enquanto reescritura está também relacionada a "algo próximo dos poderes (pessoas, instituições) que podem fomentar ou impedir a leitura, escritura e reescritura de literatura" (LEFEVERE, 2007, p. 34). A patronagem corresponderia, sob essa égide, a instituições, classes sociais, editores, mídia, entre outros, que regulamentam (promovem ou obstruem) a reescrita da literatura no mercado e na cultura de modo geral. A patronagem se sustentaria a partir de três componentes: o ideológico, o econômico e o status. No primeiro, leva-se em consideração tanto a forma quanto o conteúdo do texto reescrito; no segundo, o patrono garante um rendimento aos escritores e reescritores (tradutores) pela tarefa executada; já o terceiro, por fim, relaciona-se ao status de quem escreve ou reescreve determinados textos (Cf. LEFEVERE, 2007 , p. 35 - 36). Longe de discutirmos os pormenores e os senãos da proposta de Lefevere, como já o fizeram alguns estudiosos brasileiros (Cf. VIEIRA, 1996, p. 143 - 150; RODRIGUES, 2000, p. 103 - 132), interessa-nos, por ora, observar que existem fatores externos envolvidos no processo de tradução de um texto, que estão para além do domínio do tradutor ou reescritor, como prefere Lefevere (2007).

Logo, pressupomos que a mudança da divisão de parágrafos presente em toda a disposição do texto traduzido tenha ocorrido em virtude de uma possível interferência dos editores, responsáveis, por sua vez, pela diagramação da revista 
em que o conto foi publicado. Vale notar que, em Lefevere, a noção de patronagem está circunscrita ao campo ideológico, e o estudioso não estabelece uma possível interferência entre os fatores de patronagem e a visualidade (iconicidade) do texto/obra reescrito; mas, quando o patrono trata-se de um editor (o que possivelmente tenha ocorrido com Clarice, que no período era redatora do grupo A noite, responsável pela edição da revista Vamos Lêr), a relação não deixa de ter seus pontos convergentes, sobretudo quando observamos que, no caso de uma revista, assim como em qualquer outro texto/obra, encontramos sinais, sejam eles gráficos ou não, do contexto cultural a partir do qual foram veiculados. Afirmamos isso porque, em outros parágrafos, Lispector deixa clara a sua opção de traduzir o texto palavra por palavra, estratégia essa possibilitada, algumas vezes, até mesmo pela relação de parentesco entre as línguas em contato, como podemos observar a seguir na passagem em que o narrador francês descreve $o$ cenário da viagem feita em quatro dias:

Paul de C... n'en dit pas plus long, parce que es rocs de Such-Zen surplombaient maintenant notre route, et qu'il etait impossible de songer désormais à rien autre qu'à cette falaise sublime, hérissée d'aiguilles comme une crête de dragon, et rayée par le soleil couchant de longues ombres obliques, telle la peau d'un tigre géant (FARRÈRE, 1921, p. 20, grifo nosso).
Paul de C... não disse mais nada, porque os rochedos de Such-Zen pioravam agora o nosso caminho, e era impossível pensar daqui em diante em alguma coisa além desse magnífico penhasco, eriçado de agulhas como uma crista de dragão, e listrado pelo sol poente, com longas sombras oblíquas, tal qual a pele de um imenso tigre (FARRÈRE, 1941, p. 32, grifo nosso).

Se, por um lado, Clarice produz um texto em português muito próximo do texto de partida, por outro, como no fragmento acima, também deixa suas marcas quando traduz "surplomber" por "piorar", descartando uma primeira noção do termo francês: "dominar". Longe de prezarmos por qualquer perspectiva apoiada no "reacionário conceito de equivalência" (RODRIGUES, 2000, p. 103), a escolha da tradutora, na verdade, concede a seu texto uma maior intensidade poética, sobretudo na passagem fatigante vivida pelos personagens no caminho das rochas de território fronteiriço. Fragmentos de descrição como esses são intercalados entre alguns diálogos das personagens em deslocamento (o narrador francês e Paul de C...), bem como entre as afirmações do missionário e alguns pensamentos introspectivos, geralmente, do narrador.

No geral, Clarice não traduz os nomes das personagens e os topônimos, como ocorre em "Paul de C...", "Bois de Boulogne", "Tonkin", "Kuang-Tung" e "Kuang-Si". Paul de C... torna-se, com isso, uma das personagens mais enigmáticas da narrativa. Além de não ter um nome oriental, o personagem vietnamita é identificado pela letra "C...", assim como conhecidos personagens que povoam a literatura de Clarice: G.H. e (Rodrigo) S.M. A estratégia utilizada tanto por Farrère quanto por Lispector, em suas narrativas, traz ao texto mais ficcionalidade e um tom de mistério a ser desvendado pelo leitor, como se as iniciais dos nomes próprios funcionassem como elemento misterioso que, de certa forma, também caracterizou a vida da própria escritora-tradutora, conforme 
afirmou em crônica de 1968: "Sou tão misteriosa que não me entendo" (LISPECTOR, 1999, p. 116).

Além disso, a narrativa de Farrère remete-nos, diretamente, a duas questões importantes e relacionáveis, especialmente quando se pensa na tarefa da tradução literária em um sentido mais reflexivo: a imagem da fronteira em que o conto é ambientado e a hospitalidade que marca o comportamento do missionário. Logo no início da narrativa, o narrador claramente sugere que a fronteira, onde vive o missionário, é um entre-espaço de hospitalidade:

L'hospitalité des officiers de la frontière est proverbiale. Du coup, je ne doutai plus (FARRÈRE, 1921, p. 19).
A hospitalidade dos oficiais de fronteira é proverbial. De repente, não duvidei mais (FARRÈRE, 1941, p. 32).

Evocar a imagem da fronteira é, nesse sentido, observar que a narrativa em tradução ilustra metaforicamente um espaço de insurgência de necessidades tradutórias. Em outras palavras, o conto chama atenção, de certa forma, ao deslocamento de um narrador francês a um lugar desconhecido e estrangeiro, colocando-o em um contexto de experiência limite em que há a confluência de diversas culturas: vietnamita, chinesa, espanhola e francesa. A fronteira aqui não é apenas a linha difusa que divide a China e o Vietnã, mas o lugar relacional em que interagem o missionário espanhol que já se sente um chinês, o guia vietnamita com nome estrangeiro e o narrador francês. Então, estaria aí urdida a imagem da tradução em sua mais profícua vicissitude.

Por essas razões, a figura do missionário espanhol pode ser associada à própria imagem do tradutor, sujeito que vive nas fronteiras, sujeito em terceira margem, restando ao velho católico fora de seu lugar (a Espanha) uma única saída: receber sem restrições, proporcionando em sua própria cabana (a "própria casa") um ambiente de hospitalidade incondicional, em que o guia vietnamita e o narrador francês tiveram o que comer, onde dormir, um albergue de refúgio por toda a noite. Em outras palavras, a "hospitalidade pura consiste em acolher aquele que chega antes de lhe impor condições, antes de saber e indagar o que quer que seja, ainda que seja um nome ou um 'documento' de identidade" (DERRIDA, 2004 , p. 250). Coincidentemente, o problema da hospitalidade que emerge do conto francês não deixa de ser também um dos traços que marcam o movimento tradutório.

Conforme Derrida, os textos estrangeiros estão sempre a pedir hospitalidade em uma língua que não é a sua, impondo ao outro "um imenso e temível dever de tradução" (DERRIDA, 2004, p. 251). Essa hospitalidade realizase na medida em que o tradutor se dirige ao outro sem o imperativo das condições, assim como duplamente percebido na tradução de Clarice. Primeiro, a tarefa da tradução, por si mesma, já é uma ética de acolhimento inconteste; segundo, o texto estrangeiro traduzido por Lispector não deixa de ser, no âmbito de sua tessitura textual, uma metáfora da própria tradução como bem reitera o narrador a respeito da hospitalidade de seu hospedeiro, depois que descreve o interior da cabana missionária: 
Dans la cabane au sol de terre battue, une seule lampe brûlait, pendue au plafond par une chaîne de cuivre. Des images pieuses tapissaient les quatre murs. Le lit - une paillasse de rotin - occupait un coin. Et déjà, deux autres paillasses semblables avaient pris place à côte de celle-là, attestant l'hospitalité de notre hôte. Un enfant chinois, l'unique serviteur, tirait d'un vieux coffre du linge empilé.

- Vous êtes chez vous, - dit le missionnaire (FARRÈRE, 1921, p. 21, grifo nosso).
Na cabana de chão de terra batida, ardia uma só lâmpada, suspensa no teto por uma corrente de cobre. Imagens piedosas cobriam as quatro paredes. O leito - um enxergão de junco - ocupava o canto. E já dois outros enxergões semelhantes tinham tomado lugar ao lado daquele, atestando a hospitalidade de nosso hospedeiro.

Um menino chinês, o único criado, tirou, de uma velha arca, roupa branca empilhada.

- Estais em vossa casa, disse o missionário (FARRÈRE, 1941, p. 32 33, grifo nosso).

Quanto ao texto em português, nesse fragmento, Lispector poderia ter empregado a terceira pessoa de tratamento ao verter o pronome "vous". A opção da tradutora provoca um "enobrecimento" (Cf. BERMAN, 2013, p. 63 - 74) no texto na cultura de chegada, pois se vale de um registro mais culto em sua própria língua para retratar o primeiro contato entre $\mathrm{o}$ missionário e os viajantes ${ }^{7}$. Conforme Antoine Berman, à toda tradução subjaz um sistema de deformações que é guiado por um jogo de forças, determinando o "desejo de traduzir" (BERMAN, 2013, p. 63) do sujeito que se lança à experiência da tradução. Esse desejo, segundo Marta Marín-Dòmine (2015), está associado a uma responsabilidade (ética) do tradutor que nos possibilita ver na tradução "a marca subjetiva do tradutor” (MARÍN-DÒMINE, 2015, p. 229). Por essa razão, o ato tradutório pode ser visto como "uma experiência de falta simbólica do sujeito [tradutor] em relação à linguagem” (MARÍN-DÒMINE, 2015, p. 232), experiência essa que se esbarra na impossibilidade de recuperação completa de um sentido que, desde o texto de partida, encontra-se, de antemão, perdido. Em outros termos,

A responsabilidade não pode ser algo que se assume, simplesmente, equilibradamente, tomando sobre si ou para si a direção, a custódia ou o destino do outro [...]. A responsabilidade não consiste apenas na apropriação mais ou menos respeitosa do outro [...]. A responsabilidade teria também algo de resposta, de atenção ao chamado de um outro. Ela pode ser entendida como momento ético da tradução, como momento crítico no sentido de crise da escolha, assunto de fato pouco sublinhado e que tem

\footnotetext{
${ }^{7}$ Para um aprofundamento dessa questão, ver o ensaio "As relações perigosas na tradução: o romance Les liaisons dangereuses, de Laclos, e suas traduções brasileiras", de Germana Henriques Pereira (2013). Nele, a pesquisadora discute a questão de se traduzir o "vous" como "vós" em narrativas, na pessoa direta, em vez de "senhor", "senhora" ou "você". Para tanto, Pereira examina a tradução assinada por Carlos Drummond de Andrade do romance Les liaisons dangereuses, de Choderlos de Laclos, para analisar os efeitos causados no texto em português (Cf. PEREIRA, 2013, p. $111-112$ ).
} 
consequências reais na prática de tradução (SISCAR, 2012, p. $163)$.

Com isso, o enobrecimento presente no texto em tradução de Clarice Lispector, à luz da "analítica da tradução da prosa literária" (BERMAN, 2013, p. 67), segue uma espécie de norma suprema da elegância (Cf. BERMAN, 2013, p. 74), ainda que o texto de partida dela não compartilhe. É como se as escolhas do tradutor resultassem em uma reescritura que, inconscientemente, embeleza e traz certa aura ao texto com o qual o tradutor trava uma batalha da linguagem. A escolha de Clarice, salvo engano, também pode estar relacionada ao fato de que o discurso de um missionário é, quase sempre, atravessado por um tom religioso, ainda que esse traço não se encontre presente no texto de Farrère. Em meio a esse enobrecimento da fala do missionário hospitaleiro, podemos dizer, em amplo sentido, que o problema da hospitalidade/tradução foi uma constante desde o primeiro texto assinado pela autora. No caso da tradução publicada em 1941, essa constante reflete-se tanto no ato de traduzir em si, quanto no próprio conflito narrativo presente no texto de Farrère.

\section{A tradução como dever}

Que farei então? Deverei continuar a acertar e a errar, aceitando os resultados resignadamente? [...] Vou pensar no assunto. E certamente o resultado ainda virá sob a forma de um impulso (LISPECTOR, 1999, p. $181-182)$

O fragmento epigráfico trata da passagem final de uma crônica em que Clarice discorre sobre o seu caráter impulsivo. Esse caráter, conforme podemos notar, esteve também presente ao logo de seu projeto literário, fazendo de cada obra, de cada texto, o resultado de inúmeros impulsos, provenientes, por suas vezes, de um dever que a levava aos erros e acertos, segundo ela mesma afirma. Entre o jornalismo, a literatura e a tradução, a moça de origem ucraniana, naturalizada brasileira, sempre esteve em meio às fronteiras das literaturas e das línguas, seja quando saiu da Europa oriental ainda bebê junto com a família em direção ao Brasil, seja quando viajou pelo mundo acompanhando o esposo diplomata ou, ainda, quando se voltou à leitura e à tradução de textos estrangeiros. Parece, com isso, que a escritora de Perto do coração selvagem, desde muito jovem, esteve próxima da experiência, em constante teste/prova do estrangeiro, no sentido proposto por Berman (2002, p. 13).

Se, por um lado, outros missionários não apareceriam no plano narrativo de futuros exercícios tradutórios de Lispector, por outro, ela traduziria pelo resto da vida como quem "antes tivesse estudado de cor a representação do papel" (LISPECTOR, 1998, p. 29) do tradutor, do hospedeiro fronteiriço por excelência, ainda que essas questões talvez passassem despercebidas, à época, aos olhos receosos da crítica quanto ao aparecimento da escritora na literatura brasileira. Coincidência ou não, Lispector traduziu a narrativa do missionário e, 
sintomaticamente, assumiu, ainda que por diversas razões, a tradução como uma dívida, um dever, uma tarefa, uma missão. Uma espécie de imperativo, como afirma Derrida (2002, p. 27) a partir de Walter Benjamin (2010, p. 225).

Nesse sentido, a tarefa da tradutora coloca-lhe enquanto aquela "que tem o dever ou a tarefa de responder ao chamado do texto original, pela própria existência do texto original como texto originariamente intraduzível" (SISCAR, 2012, p. 161). Esse dever suscita na tradutora uma necessidade de tradução frente ao outro, ao estranho, ao estrangeiro, aqui, ao texto de Farrère, fazendo da tradução uma lei não unívoca que revitaliza o texto de partida e, simultaneamente, alastra o campo performático da língua da própria tradutora, como certa vez ela afirmou:

Eu queria que a língua portuguesa chegasse ao máximo nas minhas mãos. E este desejo todos os que escrevem têm. Um Camões e outros iguais não bastaram para nos dar para sempre uma herança de língua já feita. Todos nós que escrevemos estamos fazendo do túmulo do pensamento alguma coisa que lhe dê vida (LISPECTOR, 1999, p. 100, grifo da autora).

Nos meandros de um projeto múltiplo, Clarice escreveu, desde o início dos anos de 1940, sua sincopada crônica da vida literária, anunciando que à tarefa da tradução se voltou mesmo antes da publicação de seu primeiro romance. Como espécie de ato que anuncia, a tradução do pequeno conto francês do início do século vaticina à jovem jornalista e futura escritora uma atividade que marcaria $\mathrm{o}$ seu projeto intelectual ao longo dos anos: a tarefa da tradução; pois como bem afirmou Lispector, em crônica de 21 de dezembro de 1968: "Cada ser humano recebe a anunciação: e, grávido de alma, leva a mão à garganta em susto e angústia. Como se houvesse para cada um, em algum momento da vida, a anunciação de que há uma missão a cumprir" (LISPECTOR, 1999, p. 158, grifo nosso), missão essa que, em si mesma (como afirmou G.H.), é "uma missão secreta" (LISPECTOR, 1996, p. 112).

\section{Referências}

BERMAN, Antoine. A prova do estrangeiro: cultura e tradução na Alemanha romântica: Herder, Goethe, Schegel, Novalis, Humboldt, Schleiermacher, Hölderlin. Tradução de Maria Emília Pereira Chanut. Bauru, SP: EDUSC, 2002. (Coleção Signum)

. A tradução e a letra ou o albergue do longínquo. Tradução de MarieHélène Torres, Mauri Furlan e Andreia Guerini. 2 ${ }^{\mathrm{a}}$ ed. Tubarão: Copiart; Florianópolis: PGET/UFSC, 2013.

CANDIDO, Antonio. A nova narrativa. In. . A educação pela noite. $6^{\mathrm{a}}$ ed.

Rio de Janeiro: Ouro sobre Azul, 2011. p. $2 \overline{41-260 .}$ 
COUTINHO, Edilberto. Uma mulher chamada Clarice Lispector. In.

Criaturas de papel: temas de literatura \& sexo \& folclore \& carnaval \& televisão \& outros temas da vida. Rio de Janeiro/Brasília: Civilização Brasileira/INL, 1980. p. $165-170$.

DERRIDA, Jacques. O princípio da hospitalidade. In. Papel-máquina. Tradução de Evando Nascimento. São Paulo: Estação Liberdade, 2004. p. 249 252.

FARRÈRE, Claude. O missionário [Le missionnaire]. Tradução de Clarisse (sic) Lispector. In: Revista Vamos Lêr! Ano VI, n. 236. Rio de Janeiro: 6 de fevereiro de 1941. p. $32-33,64$.

. Marins et littérateurs. In. Académie française. Paris, 1946.

Disponível em http://www.academie-francaise.fr/marins-et-litterateurs. Acesso em 30.11.2018.

. Le missionnaire. In. . Contes d'outre e d'autres mondes. Paris: Librairie Dorbon-Aîné, 1921. (Les Bibliophiles Fantaisistes). p. 17 - 24.

GARBOGGINI, Flailda; CARUSO, Adalgisa. História da propaganda brasileira em revista no período da Segunda Guerra Mundial: um estudo exploratório. In:. Anais do $V$ Congresso Nacional de História da Mídia. Mídia, Indústria e Sociedade: desafios historiográficos e brasileiros. São Paulo, 31 maio a 02 de junho de 2007. p. 1 - $15 . \quad$ Disponível em: http://www.intercom.org.br/papers/outros/hmidia2007/resumos/R0214-1.pdf. Acesso em 30.11.2018.

GOTLIB, Nádia Battella. Clarice: uma vida que se conta. 6. ed. rev. e aum. São Paulo: Editora da Universidade de São Paulo, 2009.

. Clarice Fotobiografia. São Paulo: Editora da Universidade de São Paulo, Imprensa Oficial do Estado de São Paulo, 2008.

LEFEVÈRE, André. Tradução, reescrita e manipulação da fama literária. Trad. Claudia Matos Seligmann. Bauru, SP: Edusc, 2007.

LISPECTOR, Clarice. A descoberta do mundo. Rio de Janeiro: Rocco, 1999.

. A hora da estrela. Rio de Janeiro: Rocco, 1998.

. A paixão segundo G.H. Edição crítica. Coordenação de Benedito Nunes. $2^{\mathrm{a}}$ ed. Madrid; Paris; México; Buenos Aires; São Paulo; Rio de Janeiro; Lima: ALLCA XX, 1996. (Colección Archivos)

Rocco, 2007.

- Minhas queridas. Organização de Teresa Montero. Rio de Janeiro:

. Correspondências. Organização de Teresa Montero. Rio de Janeiro: Rocco, 2002. 
. Outros escritos. Organização de Teresa Montero e Lícia Manzo. Rio de Janeiro: Rocco, 2005.

MARÍN-DÒMINE, Marta. Traduzir o desejo: psicanálise e linguagem. Tradução de Emiliano de Brito Rossi. Belo Horizonte: Editora UFMG, 2015. (Humanitas)

MARTINS, Ana Luiza. Revistas em Revista: imprensa e práticas culturais em tempos de República, São Paulo (1890 - 1922). São Paulo: Editora da Universidade de São Paulo; Fapesp, 2008.

MONTERO, Teresa. $O$ Rio de Clarice: passeio afetivo pela cidade. Belo Horizonte: Editora Autêntica, 2018.

Janeiro: Rocco, 1999.

. Eu sou uma pergunta: uma biografia de Clarice Lispector. Rio de

MOSER, Benjamin. Clarice, uma biografia. Tradução de José Geraldo Couto. São Paulo: Cosac Naify, 2009.

PEREIRA, Germana Henriques. As relações perigosas na tradução: o romance Les liaisons dangereuses, de Laclos, e suas traduções brasileiras. In: FERREIRA, Alice M. de A; PEREIRA, Germana H.; GOROVITZ, Sabine (Orgs.). Tradução na sala de aula: ensaios de teoria e prática de tradução. Brasília: Editora da Universidade de Brasília, 2013. (Série Ensino de Graduação). p. 91 - 116.

RODRIGUES, Cristina Carneiro. Tradução e diferença. São Paulo: Editora UNESP, 2000. (Coleção Prismas)

SISCAR, Marcos. Jacques Derrida: literatura, política e tradução. Campinas: Autores Associados, 2012. (Ensaios e Letras)

TORRES, Marie-Hélène Catherine. Traduzir o Brasil literário: paratexto e discurso de acompanhamento. Tradução de Marlova Aseff e Eleonora Castelli. Tubarão: Copiart, 2011.

TOURY, Gideon. Descriptive Translation Studies and Beyond. Amsterdam: Benjamin, 1995

VIEIRA, Else Ribeiro Pires (Sel. e Org.). Teorizando e contextualizando a tradução. Belo Horizonte: Faculdade de Letras da UFMG, Curso de Pósgraduação em Estudos Linguísticos, 1996.

Rony Márcio Cardoso Ferreira Cardoso_Rony@hotmail.com

Germana Henriques Pereira GermanaHP@gmail.com

Recebido em: 13 out. 2018

Aceito em: 9 dez. 2018

Publicado em: 29 dez. 2018 